\title{
Immunogenic Cell Death-Based Cancer Vaccines
}

\begin{abstract}
Ming-Zhu Jin and Xi-Peng Wang*
Department of Gynecology and Obstetrics, Xinhua Hospital Affiliated to Shanghai Jiao Tong University School of Medicine, Shanghai, China
\end{abstract}

Cancer immunotherapy has achieved great advancement in the past decades. Whereas, its response is largely limited in immunologically cold tumors, in an urgent need to be solve. In recent years, an increasing number of studies have shown that inducing immunogenic cell deaths (ICDs) is an attractive approach to activate antitumor immunity. Upon specific stress, cancer cells undergo ICDs and dying cancer cells release danger associated molecular patterns (DAMPs), produce neoantigens and trigger adaptive immunity. ICDs exert a cancer vaccine-like effect and Inducement of ICDs mimics process of cancer vaccination. In this review, we propose a concept of ICDbased cancer vaccines and summarize sources of ICD-based cancer vaccines and their challenges, which may broaden the understandings of ICD and cancer vaccines in cancer immunotherapy.

Keywords: cancer vaccine, danger associated molecular patterns, immunogenic cell deaths, immunotherapy, tumor microenvironment

\section{INTRODUCTION}

Cancer treatment has shifted from tumor cell-centric to tumor microenvironment (TME)-centric with an in-depth understanding of the constitution and function of TME (1). Meanwhile, apart from targeting oncogenic pathways, there is an increasing awareness of the relationship between tumorigenesis and immunity. In the past decades, cancer immunotherapy has revolutionized cancer treatment, with immune checkpoint blockades (ICBs) including programmed cell death protein 1 (PD-1)/programmed cell death protein-ligand 1 (PD-L1)/cytotoxic T lymphocyte associate protein4 (CTLA-4) being regarded as one of the most promising approaches to treat cancer. However, ICBs do not fit all types of tumor. They encounter unresponsiveness in "cold" tumor (glioblastoma, ovarian cancer, prostate cancer, etc.), characterized by the lack of tumor antigens, T cell priming, activation or infiltration (2). Impaired $\mathrm{T}$ cell priming or activation was attributed to defective recruitment of antigen presenting cells (APCs) and lack of co-stimulatory molecules including danger associated molecular patterns (DAMPs) (3). Cancer vaccines are such a strategy which turns "cold" tumor microenvironment to "hot" one assisting to solve the therapeutic resistance of cancer immunotherapy.

Immunogenic cell death (ICD) is a unique cell death featured by activation of dying $\mathrm{T}$ cell immune response and release of DAMPs. The most frequent applied DAMPs to evaluate the immunogenicity of cell death including calreticulin (CRT), adenosine triphosphate (ATP) and high 
mobility group box 1 (HMGB1). DAMPs induced by tumor cell ICD, as mentioned before, are critical to maturation of dendritic cells (DCs), production of immunosuppressive factors, activation of APCs and T cell co-stimulation $(2,4,5)$. The characteristics of ICD provide a theoretical basis for it to be utilized to produce cancer vaccine.

Bonaventura and colleagues have provided an elaborate summary of approaches to turn "cold" tumors into "hot" ones (2). They also highlighted that ICDs induced by chemotherapy or radiotherapy and cancer vaccines are potential approaches to activate and recruit T cells (2). Herein, we will demonstrate the significance of cancer vaccines in cancer immunotherapy, highlight that ICDs can be targets for cancer vaccines and summarize current strategies of inducing ICDs. We believe that this review will provide an updated, deep and comprehensive understanding of ICD-based cancer vaccines and lead the way for cancer immunotherapy.

\section{CURRENT STATUS OF CANCER IMMUNOTHERAPY}

Thirty-five years have passed when interferon- $\alpha$ (IFN- $\alpha$ ), the first cancer immunotherapy, was approved by FDA for treating hairy cell leukemia (6). The concept of cancer immunotherapy has shifted from enhancement to normalization of antitumor immunity (7). Great progress have been made in ICBs, cancer vaccines, chimeric antigen receptor $\mathrm{T}(\mathrm{CAR}-\mathrm{T})$ cells therapies, natural killer $(\mathrm{NK})$ Cells therapies, co-stimulatory receptor agonists and cytokines in the past several decades. For example, myeloid cell TREM2 reprogrammed tumor microenvironement and the anti-TREM2 treatment promoted responsiveness of anti-PD-1 immunotherapy $(8,9)$. Personalized ovarian cancer vaccine produced neoantigen-specific $\mathrm{T}$ cells and prolonged survival of OC-bearing mice (10). CAR-NK therapy received great therapeutic responses in 11 enrolled relapsed or refractory CD19-positive cancers, without inducing major immune related adverse effects (irAE) (11). Cancer therapy has gradually entered into the era of immunotherapy. Currently, PD-1/PD-L1 monotherapies or combination therapies have been approved by FDA for first-line therapy of patients with metastatic gastric cancer and esophageal adenocarcinoma cancers, advanced renal cell carcinomas, triple-negative breast cancers, advanced lung cancer or advanced head and neck cancers. Past 5 years have even witnessed appear of neoadjuvant ICBs, which were believed to stimulate a longlasting immunomodulatory effects on diverse immune cells. Over 100 registered clinical trials on neoadjuvant ICBs were recruiting, undergoing or completed. However, despite the rapid development, cancer immunotherapy do face some challenges need to be solved. Hegde and Chen have summarized top 10 challenges for immunotherapy, including the demand in the advancement in pre-clinical models, further explorations in mechanisms of cancer immunity, assessment of its clinical efficacy, as well as investigation of its combination regimens to improve therapeutic response or reduce irAE (12). Among which, we believe that transforming immunologically cold tumors into hot ones to maximize clinical efficacy of cancer immunotherapy/ICBs is one of the hottest research focuses.

\section{CANCER VACCINES}

Cancer vaccines can be categories into genetic vaccines, protein or peptide vaccines and cell vaccines. In the past decade, the recognization of cancer vaccines in immunotherapy gradually increase, especially in its combination with ICBs. Some have already been used in clinical practice. Human papillomavirus, Hepatitis B Virus and Hepatitis C virus vaccines are applied to prevent oncogenic infections, also called prophylactic vaccine. Oncophage, a heat shock protein (HSP) vaccine, was approved in Russia for patients with earlier stage kidney cancer in 2008 (13). Sipuleucel-T (Provenge ${ }^{\circledR}$ ) was the first United States (U.S.) Food and Drug Administration (FDA)-approved cancer vaccine (2010), used to treat metastatic prostate cancer. It was a cancer vaccine manufactured with peripheral-blood mononuclear cells and a recombinant protein PA2024 through ex vivo incubation. Sipuleucel-T was reported to prolong overall survival of patients with metastatic prostate cancer, but did not delay disease progression (14). Oncophage and Sipuleucel-T are typical examples of therapeutic cancer vaccines, whose clinical realization is quite limited owing to time and cost taken to generate personalized cancer vaccine. Regardless of cancer vaccines formats, cancer vaccines aim at enhancing immunogenicity and promoting antitumor immunity to eliminate cancer cells through the induction of cancer antigens.

Cancer antigens can be classified into tumor associated antigens (TAAs), tumor specific antigens (TSAs) and cancer germline antigens (14). Non-mutant TAAs are suggested to be targets for cancer vaccines. Recently, Sahin and colleagues have tested the effect of FixVac, a liposomal RNA (RNA-LPX) vaccine that targets four non-mutated TAAs in ICB-experienced melanoma. The study showed that the RNA-LPX vaccine alone or combined with ICBs enhanced antitumor immunity, resulted in a better therapeutic response and confirmed that TAAs-based cancer vaccine could be utilized in immunotherapy (15). Whereas, there are still concerns that TAAs-based cancer vaccines encounter therapeutic resistance (central tolerance) as TAAs are generally expressed in normal cells. TSAs, also known as neoantigens, which are derived from tumor specific mutations rather than normal cells. It is believed that neoantigen-based cancer vaccines may be safer, more effective and more likely to spare from resistance, bringing cancer vaccine back to research focus after two decades when cancer vaccine clinical trials encountered a low objective response rate (16). Classified by sources, classical neoantigen-based cancer vaccines include but not limited to synthetic long peptide (SLP) vaccines, DC vaccines, RNA vaccines. In a phase I/Ib surgical resectable methylguanine methyltransferase-unmethylated glioblastoma trial, Keskin and colleagues have shown that SLP vaccination do lead to neoantigen-specific $\mathrm{T}$ cell infiltration and response in tumor microenvironment, which sensitizes immunotherapy in tumors 
that originally with low tumor burden and immunogenicity (17, 18). Though, unfortunately all the enrolled patients could not spare from death because of tumor progression and recurrence (18), TSA-based cancer vaccines do arouse great attention. There is an urgent need for broaden understandings of vaccine-induced TSAs in stimulating immunity and improvements in manufacturing TSA-based cancer vaccines.

\section{INDUCING IMMUNOGENIC CELL DEATH TO GENERATE CANCER VACCINATION}

\section{Immunogenic Cell Death: A Form of Immunogenic Regulated Cell Death}

ICDs, contrary to tolerogenic or non-immunogenic cell deaths, are a form of regulated cell deaths that trigger adaptive immunity through production of neoantigens and release of DAMPs and cytokines. Thus, immunogenicity of cancer cell deaths in vitro is evaluated by immunostimulatory DAMPs like HMGB1, ATP, CRT, HSP70, HSP90, ANXA1, or cytokines like IFN, CCL2, CXCL1, CXCL10, etc (19). Meanwhile, the vaccinationrechallenge model is applied to detect ICDs in vivo. ICDs were initially found to be triggered by chemotherapy or radiation, while accumulative evidence has shown that they can be induced by photodynamic therapy (PDT), targeted therapy, oncolytic viruses, cardiac glycosides, as well as shikonin and capsaicin, extracts of Chinese herbal medicine. The inducement of ICDs and the production of neoantigens reshapes immunosuppressive TME to immunoactivited one, initiate antitumor immunity and improve therapeutic response of immunotherapy. ICD-based therapy is now viewed as attractive candidates for cancer immunotherapy combination regimens.

\section{ICD Induction Realizes Cancer Vaccine- Like Effect}

Upon particular stress like chemotherapy, radiotherapy, ICD cascade initiates including generation of tumor specific neoantigens by dying cancer cells, generation of ROS, induction of ER stress, release of DAMPs including exposure of CRT on cell surface (activation of "eat me" signal), secretion of ATP and HMGB1. DAMPs are then recognized by pattern recognition receptors (PRRs), promoting recruitment and maturation of DCs (Figure 1). The mature DCs then uptake dying cells, process TSAs to APCs, promote T cells polarizations, engulf CTLs, $\mathrm{CD} 4^{+} \mathrm{T}$ cells, which leads to production of cytokines and activation of antitumor immunity ultimately $(4,5)$ (Figure 1). During the process, dying cancer cells

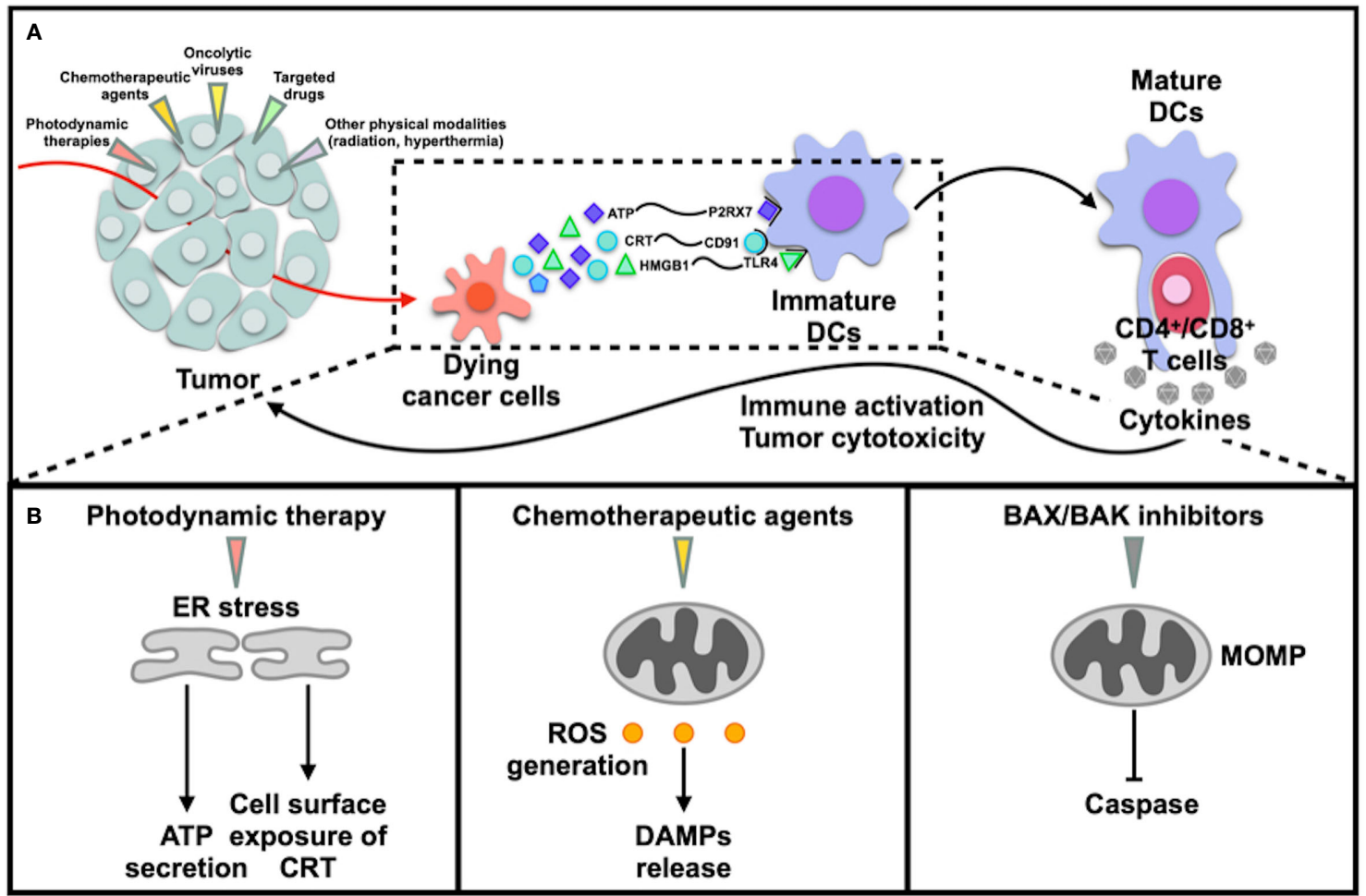

FIGURE 1 | Immunogenic cancer death. (A) Various triggers like photodynamic therapies, chemotherapeutic agents, oncolytic viruses, targeted drugs and physical modalities induce immunogenic cell deaths and release of DAMPs, leading to immune activation; (B) ICDs were induced via different mechanisms: 1) induction of ER stress directly cause cell deaths; 2) generation of ROS, in which induction of ER stress does not directly cause ICDs; 3) induction of mitochondrial outer membrane permeabilization (MOMP). 
generate antigens and enhance immunogenicity to kill tumor cells, in line with the criterion of endogenous cancer vaccines. Recruited DCs may serve as be effective targets for cancer vaccine as well, which is DC vaccine that we are familiar with.

\section{ICD Detection Relies on the Vaccination- Rechallenge Experiment}

Immunogenicity of cell deaths induced by therapeutic agents can be assessed in vivo and in vitro through quantitative analysis of CRT exposure, ATP and HMGB1 secretion, ROS generation or ER stress. At present, there is no specific structure that helps to predict potential ICD inducers. The gold standard experiment to validate ICD or verify an ICD inducer is the vaccinationrechallenge experiment: cancer cells were treated with a potential ICD inducer and cell viability was assessed via cytometry after staining with PI and annexin $\mathrm{V} \mathrm{DIOC}_{6}$ (Figure 2B). Most of non-dead cancer cells should be at a dying stage. Cell suspension was then injected subcutaneously to immunocompetent mice, which is called vaccination. Living cancer cells were injected a week later, which is called rechallenge. Tumor volumes of mice post-vaccination to postrechallenge and the ratio of mice spared from tumor formation were recorded (20). The vaccination-rechallenge experiment not only helps to identify an ICD inducer, but also builds a prototype for vaccination with ICD cells.

\section{APPROACHES TO PRODUCE IMMUNOGENIC CELL DEATH-BASED CANCER VACCINES}

ICD can be triggered by PDT (21), chemotherapeutic agents (18, 22-31), oncolytic viruses (OVs) (32-34) and targeted drugs (3538) (Table 1), as well as physical modalities such as radiation (52), hyperthermia (53), which won't be discussed herein. In this review, we divide ICD-based cancer vaccines into two categories: ICD inducers (Figure 2A) and ICD cells (Figure 2B).

\section{Vaccination With ICD Inducers: Photodynamic Therapy}

PDT has been proved to have anti-tumor and immuneactivation effect in various types of cancers such as cervical cancer, pancreatic cancer, prostate cancer, glioblastoma and clinically approved in treating non-small cell lung cancers and esophageal cancers by the U.S. FDA. PDT requires a lightsensitive dye, also known as a photosensitizer (PS). With the presence of light of specific wavelength (600-900 nm) and oxygen, PDT is able to generate reactive oxygen species (ROS) and cause cell death through inducing endoplasmic reticulum (ER) stress $(54,55)$.

It is worth noting that PDT's effect on inducing ICDs and enhance tumor immunogenicity is reduced in hypoxic niche $(21$,

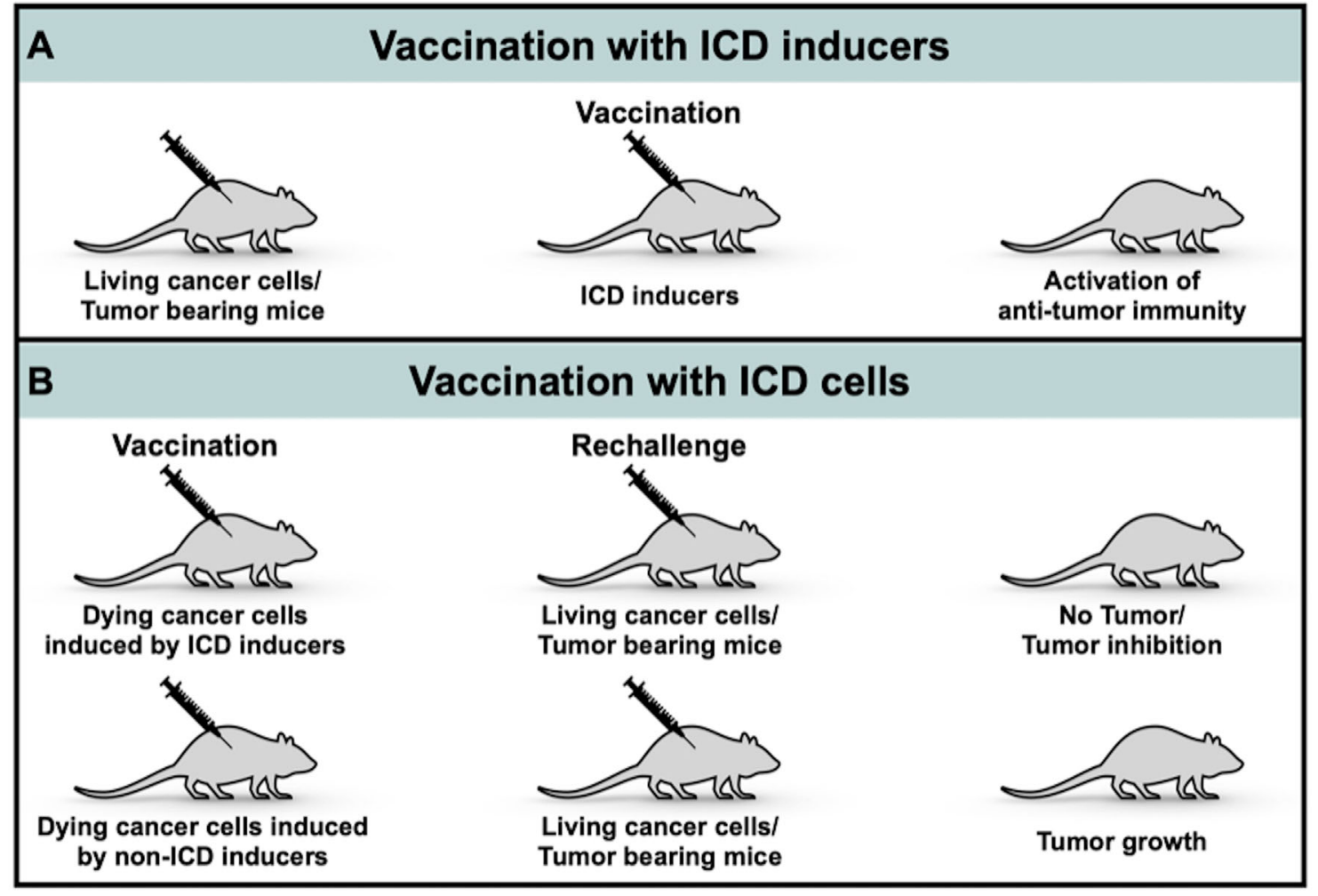

FIGURE 2 | Process of inducing ICD-based cancer vaccines. (A) Vaccination with ICD inducers; (B) Vaccination with ICD cells. 
TABLE 1 | Examples of immunogenic cell death-based cancer vaccine.

\begin{tabular}{|c|c|c|c|c|c|c|c|c|c|c|c|}
\hline Categories & Examples & $\begin{array}{l}\text { Cell } \\
\text { lines }\end{array}$ & $\begin{array}{l}\text { Vaccination- } \\
\text { challenge } \\
\text { experiment }\end{array}$ & $\begin{array}{c}\text { ROS } \\
\text { generation }\end{array}$ & ER stress & $\begin{array}{c}\text { Biomarkers } \\
\text { (DAMPs) for } \\
\text { identifying } \\
\text { ICDs }\end{array}$ & $\begin{array}{l}\text { Cytokines } \\
\text { secretion }\end{array}$ & $\begin{array}{l}\text { Antitumor immunity } \\
\text { activation }\end{array}$ & Other observations & $\begin{array}{l}\text { Type of } \\
\text { ICDs }\end{array}$ & Ref \\
\hline $\begin{array}{l}\text { Photodynamic } \\
\text { therapies-derived } \\
\text { cancer vaccine }\end{array}$ & $\begin{array}{l}\text { PS-PDT; } \\
\text { PD-PDT; } \\
\text { FAL-ICG-HAuNS; } \\
\text { AuNC@MnO2, AM; } \\
\text { Ce6/MLT@SAB; } \\
\text { CCPS; } \\
\text { pRNVs/HPPH/IND; } \\
\text { Ds-sP/TCPP-TER } \\
\text { NPs) }\end{array}$ & $\begin{array}{l}\text { 4T1; } \\
\text { B16; } \\
\text { CT-26; } \\
\text { MC38; } \\
\text { GL261; } \\
\text { MCA205 }\end{array}$ & $+/-$ & + & $\begin{array}{l}\text { +/not } \\
\text { mentioned }\end{array}$ & $\begin{array}{l}\text { CRT } \\
\text { exposure; } \\
\text { ATP release; } \\
\text { HMGB1 } \\
\text { release }\end{array}$ & $\begin{array}{l}\text { IL-6; } \\
\text { IL-12; } \\
\text { TNF- } \alpha \text {; } \\
\text { IFN- } \gamma\end{array}$ & $\begin{array}{l}\text { Recruitment, maturation } \\
\text { and activated antigen } \\
\text { presenting functions of } \\
\text { DCs; } \\
\text { Recruitment, infiltration, } \\
\text { proliferation and } \\
\text { activation of CTLs; } \\
\text { Activation of CD4 }{ }^{+} T \\
\text { cells (mostly Tregs) and } \\
\text { NK cells activation; } \\
\text { Inhibition of MDSCs } \\
\text { proliferation }\end{array}$ & $\begin{array}{l}\text { CHOP proteins upregulation; } \\
\text { Relieve of hypoxic niche; } \\
\text { Caspase-3 activation; } \\
\text { PI3K-Akt pathway activation; } \\
\text { IDO upregulation }\end{array}$ & $\begin{array}{l}\text { Apoptosis; } \\
\text { Ferroptosis; } \\
\text { Necrosis }\end{array}$ & $\begin{array}{c}(21 \\
39-43)\end{array}$ \\
\hline $\begin{array}{l}\text { Chemotherapeutic } \\
\text { agents-derived } \\
\text { cancer vaccine }\end{array}$ & $\begin{array}{l}\text { Doxorubicin; } \\
\text { Bortezomib; } \\
\text { Melphalan; } \\
\text { Paclitaxel }\end{array}$ & $\begin{array}{l}\text { EG7; } \\
\text { CT26; } \\
\text { PROb; } \\
\text { B16; } \\
\text { U266; } \\
\text { GL261; }\end{array}$ & + (Mostly) & + & $\begin{array}{l}\text { Not } \\
\text { mentioned } \\
\text { in most } \\
\text { researches }\end{array}$ & $\begin{array}{l}\text { CRT } \\
\text { exposure; } \\
\text { ATP release; } \\
\text { HMGB1 } \\
\text { release; } \\
\text { HSP70 } \\
\text { exposure; } \\
\text { HSP90 } \\
\text { exposure; } \\
\text { F-actin } \\
\text { exposure }\end{array}$ & $\begin{array}{l}\text { IFN- } \gamma, \mathrm{IL}- \\
1 \beta \\
\mathrm{IL}-6\end{array}$ & $\begin{array}{l}\text { Maturation and } \\
\text { proliferation of DCs; } \\
\text { Proliferation. infiltration } \\
\text { of CTLs; Proliferation of } \\
\text { NK cells; } \\
\text { Proliferation and } \\
\text { polarization of } \\
\text { macrophages; }\end{array}$ & $\begin{array}{l}\text { Caspase-3 activation; } \\
\text { Activation of NF-kB-mediated CCL2 } \\
\text { transcription; Activated vesicle } \\
\text { exocytosis induced by lkappaB- } \\
\text { mediated SNARE; }\end{array}$ & Apoptosis & $\begin{array}{c}(22, \\
24,25, \\
27,31, \\
44)\end{array}$ \\
\hline $\begin{array}{l}\text { Oncolytic viruses- } \\
\text { derived cancer } \\
\text { vaccine }\end{array}$ & $\begin{array}{l}\text { Semliki Forest virus; } \\
\text { Vaccinia virus; } \\
\text { Adenovirus; } \\
\text { Measles virus; } \\
\text { Coxsackievirus B3; } \\
\text { Newcastle disease } \\
\text { virus; } \\
\text { Seasonal Influenza } \\
\text { Vaccine }\end{array}$ & $\begin{array}{l}\text { B16; } \\
\text { HOS; } \\
\text { A549; } \\
\text { CT26; } \\
\text { MeWo; } \\
\text { PANO2; } \\
\text { CMT93; } \\
\text { Mel888; } \\
\text { Mel624; } \\
\text { SkMel28 }\end{array}$ & + & + & $\begin{array}{l}\text { Not } \\
\text { mentioned } \\
\text { in most } \\
\text { researches }\end{array}$ & $\begin{array}{l}\text { CRT } \\
\text { exposure; } \\
\text { ATP release; } \\
\text { HMGB1 } \\
\text { release; } \\
\text { HSP90 } \\
\text { exposure; }\end{array}$ & $\begin{array}{l}\text { IFN- } \alpha \text {; } \\
\text { IFN- } \beta \text {; } \\
\text { IFN- } \gamma \text {; } \\
\text { IL-12; } \\
\text { TNF- } \alpha \text {; } \\
\text { IL-4; } \\
\text { IL-13; } \\
\text { IL-6; } \\
\text { IL-8; } \\
\text { IL-1 } \beta ; \\
\text { IL-24; } \\
\text { CCL3 }\end{array}$ & $\begin{array}{l}\text { Activation and } \\
\text { maturation of DCs; } \\
\text { Recruitment and } \\
\text { activation of tumor } \\
\text { antigen-specific CTLs; } \\
\text { Maintenance of Bregs; }\end{array}$ & $\begin{array}{l}\text { Release of PAMPs; } \\
\text { Activation of PI3K/Akt and MAP/ } \\
\text { ERK/MEK pathway; } \\
\text { Release of tumor specific } \\
\text { neoantigens }\end{array}$ & $\begin{array}{l}\text { Apoptosis; } \\
\text { Necroptosis; } \\
\text { Pyroptosis; } \\
\text { Autophagy; }\end{array}$ & $\begin{array}{c}(33 \\
34 \\
45-50)\end{array}$ \\
\hline $\begin{array}{l}\text { Targeted drugs- } \\
\text { derived cancer } \\
\text { vaccine }\end{array}$ & $\begin{array}{l}\text { 7A7 mAb; } \\
\text { Cetuximab; } \\
\text { Crizotinib }\end{array}$ & $\begin{array}{l}\text { D122; } \\
\text { H1650; }\end{array}$ & + & $\begin{array}{l}\text { Not } \\
\text { mentioned }\end{array}$ & + & $\begin{array}{l}\text { CRT } \\
\text { exposure; } \\
\text { ATP release; } \\
\text { HMGB1 } \\
\text { release; } \\
\text { HSP 70 } \\
\text { exposure; } \\
\text { HSP 90 } \\
\text { exposure; }\end{array}$ & $\begin{array}{l}\text { IFN- } \alpha \\
\text { IFN- } \gamma \\
\text { IL-12; } \\
\text { IL-17; }\end{array}$ & $\begin{array}{l}\text { Activation and } \\
\text { maturation of DCs; } \\
\text { Proliferation, infiltration } \\
\text { and activation of CTLs; } \\
\text { Promotion of DCs } \\
\text { phagocytosis of dying } \\
\text { cells; } \\
\text { Induction of PD-1 } \\
\text { expression on tumor- }\end{array}$ & Inhibition of XBP1 & Apoptosis & $\begin{array}{l}(35- \\
37)\end{array}$ \\
\hline
\end{tabular}




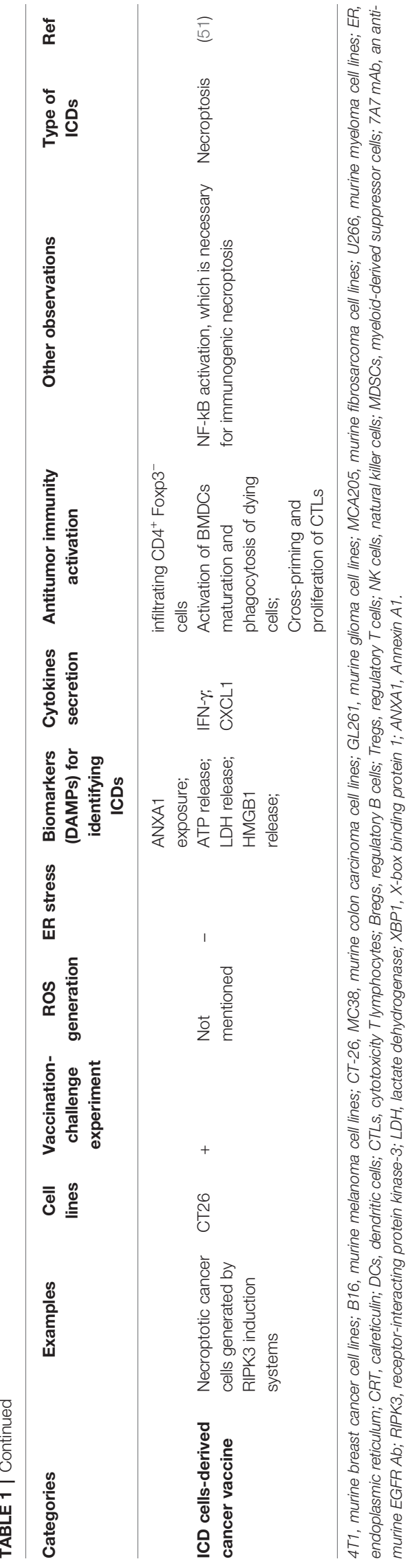

56). Meanwhile, PDT exacerbates hypoxia in TME, leading to angiogenesis, tumor progression, metastasis, poor therapeutic response and prognosis $(56,57)$. Researchers have been trying to solve the problem by developing an oxygen nanocarrier with chlorine e6 encapsulated (C@HPOC) (58). The modified oxygen-boosted PDT displayed infiltration of cytotoxic T lymphocytes (CTLs) in TME and a better induction of ICD in 4T1 murine breast cancer cells by elevating cell surface exposure of CRT, increasing release of HMGB1 and ATP, and afterwards promoting the maturation of DCs (57). Combing metal-organic framework-based nanoparticles to PDT was also of benefit for alleviating PDT-induced hypoxia via inhibiting hypoxia inducible factor-1 $\alpha$ (59). The combination of nanomaterials or anti-hypoxic treatment with PDT may help it to achieve a better clinical realization.

\section{Vaccination With ICD Inducers: Chemotherapeutic Agents}

The initial hypothesis on the relationship between chemotherapy and ICDs could date back to one or two decades ago. It was proposed that the impact of chemotherapy on immune system through induction of ICDs helped it to achieve better clinical efficacy (18). However, not all kinds of chemotherapeutic agents induce ICDs, and some chemotherapeutic agents do have immunogenic effects, but insufficient to cause cell death (28). So far, anthracyclins (22), bleomycin (23), bortezomib (24), cyclophosphamide $(25,26)$, daunorubicin $(22)$, doxorubicin (22), idarubicin (22), melphalan (27), oxaliplatin (31), paclitaxel (44) and trifluridine/tipiracil (29) have been proved to induce ICDs; while, cisplatin, mitomycin $\mathrm{C}$ were proved to induce non-immunogenic apoptosis $(22,28)$. The reason remains unknown, even though oxaliplatin and cisplatin share similar structures, which raises the bar for seeking out an ICD inducer and confirms the significance of vaccinerechallenge experiment.

Mechanisms in inducing ICDs for chemotherapeutic agents are different from those for PDT. Instead of inducing ICDs directly through ER stress, chemotherapeutic agents tend to induce generation of ROS. Based on the difference, Wang et al. have divided ICD inducer into two types: type I for those inducing ROS generation (chemotherapeutic agents/targeted therapy), type II for those inducing ER stress (PDT/Oncolytic viruses) (60). Notably, cancer vaccination effects induced by chemotherapeutic agents are weaker than PDT. Take melphalan as an example, hypericin photodynamic therapy (Hyp-PDT) as a positive control, brefeldin A (a tolerogenic cell death inducer) as a negative control, melphalan-induced cancer vaccination effect was in the middle with $40 \%$ vaccinated mice protected (62\% for Hyp-PDT group, less than 20\% for brefeldin A group) (27). However, apart from its cytotoxicity to kill tumor cells directly, chemotherapeutic agents have their advantages compared to ICD inducer in being a cancer vaccine: their extensive role on non-malignant cells in immunosuppressive TME and additional immunogenic effect other than ICDs, which may be utilized to realize better tumorkilling effect (30). 


\section{Vaccination With ICD Inducers: Oncolytic Viruses}

OVs have become attractive formats of cancer vaccine in immunotherapy considering its direct cytotoxicity mediated by oncolysis, immune activation and anti-angiogenesis (61). Even intratumoral injections of OVs have been proved to activate antitumor immunity not only inside tumors and on adjacent TME, but also on distant untreated focuses (62). Previous studies have revealed that oncolytic viruses such as Coxsackievirus B3, Adenovirus, Measles virus, Semliki Forest virus, Newcastle disease virus, influenza A virus elicit ICDs (33, 34, 45-47, 50) and improve immune responses of ICBs $(48,49)$. The additional release of pathogen-associated molecular patterns (PAMPs) derived from oncolytic viruses further increases immuneactivation (63).

Specially, the combination of oncolytic viruses and chemotherapeutic agents have been shown to maximize immunogenicity. For example, the combination of adenovirus and oxaliplatin, both demonstrated to be ICD inducers in colorectal cancer in previous studies $(31,47)$, leaded to reduced tumor growth and longer median survival CT26 (mouse rectal adenocarcinoma cell line)-bearing mice compared to adenovirus or oxaliplatin alone (64). Instead of systemic administration, researchers chose intratumoral injection via interventional radiologic techniques to peruse a high local concentration sufficient to cause ICDs and a relatively low systemic toxicity. Meanwhile, a replicating other than a nonreplicating virus was required to overcome transient growth inhibitions and achieve sustained tumor suppressive activity; buffer for oxaliplatin needed to be carefully selected considering its impact on increasing cytotoxicity of oxaliplatin and reducing infectivity of adenovirus (64). These findings confirm synergistic effects of two ICD inducers and provide guidance when one single ICD inducer does not sufficient to provide a strong and long-lasting immune-activation.

\section{Vaccination With ICD Inducers: Targeted Drugs}

Epidermal growth factor receptor (EGFR)-targeting mAb 7A7 or cetuximab and tyrosine kinase inhibitor crizotinib were reported to exert ICDs $(35-38,52)$. EGFR-targeting mAb 7A7 exert an effect on DCs, T cells and NK cells infiltration (65). The combination of targeted drugs and chemotherapy, for example cetuximab plus folinic acid+fluorouracil+irinotecan (FOLFIRI) or crizotinib plus cisplatin), resulted in a better antitumor efficacy (36-38). Cetuximab's ability of inducing ICDs relies on EGFR mutational status and BRAF mutation. It failed to induce ICDs in human colon cancer cells (HT-30 cells lines) (KRAS ${ }^{\mathrm{WT}}$ ) (37). These provide explanations for heterogeneous or limited therapeutic efficacy of some targeted drugs when applied as a single agent to some extent. Liu and colleagues also showed that crizotinib and cisplatin combination upregulated expression of PD-1/PD-L1 and improved therapeutic response to ICBs (37, 38). However, targeted therapy in inducing ICDs is still at a beginning stage calling for more attempts and scientific evidence.

\section{Vaccination With ICD Cells}

Expect vaccination with ICD-inducers, vaccination with ICD cells also realizes a cancer vaccine-like effect, which mimics the establishment of vaccination-rechallenge model (Figure 2B). Immunocompetent mice were vaccinated with doxycyclinetreated necroptotic DD_RIPK3 cells (51). Injected necroptotic cells leaded to the generation of TSAs, proliferation of CTLs, release of HMGB1, production of cytokines like $\mathrm{CXCL}_{1}, \mathrm{IFN}-\gamma$ and phenotypic maturation of bone marrow-derived DCs. Remarkably, NF- $\kappa \mathrm{B}$ activation but not ER stress was observed in necroptotic cells, indicating immunogenicity of DD_RIPK3 cells was not principally mediated by ER stress, which was a little bit different from up-mentioned classical ICDs (51). Strategies that elevated RIPK3 expression were required since losses of RIPK3 expression exists in many types of cancer and genotypes of ICD cells largely restrict their immunogenicity $(6,51)$. Compared to ICD inducers, utilizing ICD cells is more able to produce personalized cancer vaccines, but more time-consuming and money-consuming.

\section{DISCUSSION}

ICDs generate tumor specific antigens, which serves as endogenous cancer vaccine targets. Recent years, especially last year, have witnessed a growing utilization of nanoparticles in delivering ICD inducers or amplifying cancer cell ICDs. Advantages of ICD-based cancer vaccines are quite obvious. First and foremost, they arouse immunogenicity for "cold" tumor and sensitize immunotherapy. Secondly, their immune stimulation activities reach to distant untreated lesions, which means intratumorally injection with a lower-dose may be chosen to avoid systemic cytotoxicity. Apart from up-mentioned a great variety of inducers, other therapeutic agents such as cardiac glycosides (66), non-steroidal anti-inflammatory drugs (NSAIDs) (67), dinaciclib (an experimental inhibitor of cyclin-dependent kinases) (68) displayed ability to induce ICDs as well.

However, it is still difficult to look for a candidate in a bundle of drugs. Recognitions of universality of ICD inducers, ICD biomarkers and platforms for efficient, time-saving, moneysaving, high-throughput drug screening may accelerate drug discoveries. What's more, we have noticed heterogeneous capability of activating anti-tumor immunity. As reviewed previously, TME is made up of various specialized micro environments (1), and there is an intricate crosstalk between each other. Besides fighting against immunosuppressive TME, ICD-based cancer vaccine needs to overcome hypoxia as well to realize a stable and long-lasting effect. Jessup and colleagues have combined two ICD inducers to achieve better immune responses (64). Chen et al. (58) and Cai et al. (59) have worked on modifying the PS with nanoparticles or combining anti-hypoxia treatment to overcome hypoxia in TME as mentioned before. They have set good examples for magnifying clinical effect of ICD-based cancer vaccines. The clinical realization of ICD-based cancer vaccines relies on a deeper investigation of their mechanisms 
not merely on tumor immunity or immune microenvironment but also on the whole TME, and more attentions and attempts on combination therapy. It is noteworthy that previous studies haven't take irAE into consideration. Questions like how severe are irAE of ICD-based cancer vaccines or what kinds of people tend to suffer from irAE call for answers. Also, we've noticed that ICDs include apoptosis, ferroptosis, necrosis, autophagy, which may exert a different impact on immunity (69), whereas, few studies take modes of cell deaths into considerations.

In general, the concept that ICD can be competitive cancer vaccine targets provides a solid theoretical basis for application of ICD-based cancer vaccine in "cold" tumor and broadens understandings and approaches for investigation of neoantigen-based cancer vaccine. Owing to immunogenicity induced by ICDs, ICD-based cancer vaccines will be appealing sensitizers for ICBs in the near future.

\section{REFERENCES}

1. Jin MZ, Jin WL. The Updated Landscape of Tumor Microenvironment and Drug Repurposing. Signal Transduct Target Ther (2020) 5(1):166. doi: 10.1038/s41392-020-00280-x

2. Bonaventura P, Shekarian T, Alcazer V, Valladeau-Guilemond J, ValsesiaWittmann S, Amigorena S, et al. Cold Tumors: A Therapeutic Challenge for Immunotherapy. Front Immunol (2019) 10:168. doi: 10.3389/ fimmu.2019.00168

3. Akira S, Uematsu S, Takeuchi O. Pathogen Recognition and Innate Immunity. Cell (2006) 124(4):783-801. doi: 10.1016/j.cell.2006.02.015

4. Green DR, Ferguson T, Zitvogel L, Kroemer G. Immunogenic and Tolerogenic Cell Death. Nat Rev Immunol (2009) 9(5):353-63. doi: $10.1038 /$ nri2545

5. Kroemer G, Galluzzi L, Kepp O, Zitvogel L. Immunogenic Cell Death in Cancer Therapy. Annu Rev Immunol (2013) 31:51-72. doi: 10.1146/annurevimmunol-032712-100008

6. Quesada JR, Hersh EM, Manning J, Reuben J, Keating M, Schnipper E, et al. Treatment of Hairy Cell Leukemia With Recombinant Alpha-Interferon. Blood (1986) 68(2):493-7. doi: 10.1182/blood.V68.2.493.bloodjournal682493

7. Sanmamed MF, Chen L. A Paradigm Shift in Cancer Immunotherapy: From Enhancement to Normalization. Cell (2018) 175(2):313-26. doi: 10.1016/ j.cell.2018.09.035

8. Molgora M, Esaulova E, Vermi W, Hou J, Chen Y, Luo J, et al. TREM2 Modulation Remodels the Tumor Myeloid Landscape Enhancing Anti-PD-1 Immunotherapy. Cell (2020) 182(4):886-900.e17. doi: 10.1016/ j.cell.2020.07.013

9. Katzenelenbogen Y, Sheban F, Yalin A, Yofe I, Svetlichnyy D, Jaitin DA, et al. Coupled scRNA-Seq and Intracellular Protein Activity Reveal an Immunosuppressive Role of TREM2 in Cancer. Cell (2020) 182(4):872-85 e19. doi: 10.1016/j.cell.2020.06.032

10. Tanyi JL, Chiang CL, Chiffelle J, Thierry AC, Baumgartener P, Huber F, et al. Personalized Cancer Vaccine Strategy Elicits Polyfunctional T Cells and Demonstrates Clinical Benefits in Ovarian Cancer. NPJ Vaccines (2021) 6 (1):36. doi: 10.1038/s41541-021-00297-5

11. Liu E, Marin D, Banerjee P, Macapinlac HA, Thompson P, Basar R, et al. Use of CAR-Transduced Natural Killer Cells in CD19-Positive Lymphoid Tumors. N Engl J Med (2020) 382(6):545-53. doi: 10.1056/NEJMoa1910607

12. Hegde PS, Chen DS. Top 10 Challenges in Cancer Immunotherapy. Immunity (2020) 52(1):17-35. doi: 10.1016/j.immuni.2019.12.011

13. Itoh K, Yamada A, Mine T, Noguchi M. Recent Advances in Cancer Vaccines: An Overview. Jpn J Clin Oncol (2009) 39(2):73-80. doi: 10.1093/jjco/hyn132

14. Kantoff PW, Higano CS, Shore ND, Berger ER, Small EJ, Penson DF, et al. Sipuleucel-T Immunotherapy for Castration-Resistant Prostate Cancer. N Engl J Med (2010) 363(5):411-22. doi: 10.1056/NEJMoa1001294

\section{AUTHOR CONTRIBUTIONS}

X-PW and M-ZJ conceived the paper. M-ZJ wrote the paper and developed the figures and tables. X-PW edited the paper. All authors contributed to the article and approved the submitted version.

\section{FUNDING}

$\mathrm{X}-\mathrm{PW}$ is supported by the National Natural Science Foundation of China (Nos. 81874103 and 81930064).

\section{ACKNOWLEDGMENTS}

Thanks to Prof. Weilin Jin for offering help and providing useful suggestions during accomplishment of the manuscript.

15. Sahin U, Oehm P, Derhovanessian E, Jabulowsky RA, Vormehr M, Gold M, et al. An RNA Vaccine Drives Immunity in Checkpoint-Inhibitor-Treated Melanoma. Nature (2020) 585(7823):107-12. doi: 10.1038/s41586-020-2537-9

16. Rosenberg SA, Yang JC, Restifo NP. Cancer Immunotherapy: Moving Beyond Current Vaccines. Nat Med (2004) 10(9):909-15. doi: 10.1038/nm1100

17. Yarchoan M, Hopkins A, Jaffee EM. Tumor Mutational Burden and Response Rate to PD-1 Inhibition. N Engl J Med (2017) 377(25):2500-1. doi: 10.1056/ NEJMc1713444

18. Keskin DB, Anandappa AJ, Sun J, Tirosh I, Mathewson ND, Li S, et al. Neoantigen Vaccine Generates Intratumoral T Cell Responses in Phase Ib Glioblastoma Trial. Nature (2019) 565(7738):234-9. doi: 10.1038/s41586-0180792-9

19. Galluzzi L, Vitale I, Warren S, Adjemian S, Agostinis P, Martinez AB, et al. Consensus Guidelines for the Definition, Detection and Interpretation of Immunogenic Cell Death. J Immunother Cancer (2020) 8(1):1-21. doi: 10.1136/jitc-2019-000337

20. A López-Soto, AR Folgueras eds. Cancer Immunosurveillance: Methods and Protocols. New York, NY: Humana Press (2019).

21. Li W, Yang J, Luo L, Jiang M, Qin B, Yin H, et al. Targeting Photodynamic and Photothermal Therapy to the Endoplasmic Reticulum Enhances Immunogenic Cancer Cell Death. Nat Commun (2019) 10(1):3349. doi: 10.1038/ s41467-019-11269-8

22. Casares N, Pequignot MO, Tesniere A, Ghiringhelli F, Roux S, Chaput N, et al. Caspase-Dependent Immunogenicity of Doxorubicin-Induced Tumor Cell Death. J Exp Med (2005) 202(12):1691-701. doi: 10.1084/jem.20050915

23. Bugaut H, Bruchard M, Berger H, Derangere V, Odoul L, Euvrard R, et al. Bleomycin Exerts Ambivalent Antitumor Immune Effect by Triggering Both Immunogenic Cell Death and Proliferation of Regulatory T Cells. PloS One (2013) 8(6):e65181. doi: 10.1371/journal.pone.0065181

24. Spisek R, Charalambous A, Mazumder A, Vesole DH, Jagannath S, Dhodapkar MV. Bortezomib Enhances Dendritic Cell (DC)-Mediated Induction of Immunity to Human Myeloma Via Exposure of Cell Surface Heat Shock Protein 90 on Dying Tumor Cells: Therapeutic Implications. Blood (2007) 109(11):4839-45. doi: 10.1182/blood-2006-10-054221

25. Wu J, Waxman DJ. Metronomic Cyclophosphamide Eradicates Large Implanted GL261 Gliomas by Activating Antitumor Cd8(+) T-Cell Responses and Immune Memory. Oncoimmunology (2015) 4(4):e1005521. doi: 10.1080/2162402X.2015.1005521

26. Schiavoni G, Sistigu A, Valentini M, Mattei F, Sestili P, Spadaro F, et al. Cyclophosphamide Synergizes With Type I Interferons Through Systemic Dendritic Cell Reactivation and Induction of Immunogenic Tumor Apoptosis. Cancer Res (2011) 71(3):768-78. doi: 10.1158/0008-5472.CAN10-2788

27. Dudek-Peric AM, Ferreira GB, Muchowicz A, Wouters J, Prada N, Martin S, et al. Antitumor Immunity Triggered by Melphalan is Potentiated by 
Melanoma Cell Surface-Associated Calreticulin. Cancer Res (2015) 75 (8):1603-14. doi: 10.1158/0008-5472.CAN-14-2089

28. Vanmeerbeek I, Sprooten J, De Ruysscher D, Tejpar S, Vandenberghe P, Fucikova J, et al. Trial Watch: Chemotherapy-Induced Immunogenic Cell Death in Immuno-Oncology. Oncoimmunology (2020) 9(1):1703449. doi: 10.1080/2162402X.2019.1703449

29. Limagne E, Thibaudin M, Nuttin L, Spill A, Derangere V, Fumet JD, et al. Trifluridine/Tipiracil Plus Oxaliplatin Improves PD-1 Blockade in Colorectal Cancer by Inducing Immunogenic Cell Death and Depleting Macrophages. Cancer Immunol Res (2019) 7(12):1958-69. doi: 10.1158/ 2326-6066.CIR-19-0228

30. Galluzzi L, Buque A, Kepp O, Zitvogel L, Kroemer G. Immunological Effects of Conventional Chemotherapy and Targeted Anticancer Agents. Cancer Cell (2015) 28(6):690-714. doi: 10.1016/j.ccell.2015.10.012

31. Tesniere A, Schlemmer F, Boige V, Kepp O, Martins I, Ghiringhelli F, et al. Immunogenic Death of Colon Cancer Cells Treated With Oxaliplatin. Oncogene (2010) 29(4):482-91. doi: 10.1038/onc.2009.356

32. Diaconu I, Cerullo V, Hirvinen ML, Escutenaire S, Ugolini M, Pesonen SK, et al. Immune Response is an Important Aspect of the Antitumor Effect Produced by a CD40L-Encoding Oncolytic Adenovirus. Cancer Res (2012) 72 (9):2327-38. doi: 10.1158/0008-5472.CAN-11-2975

33. Miyamoto S, Inoue H, Nakamura T, Yamada M, Sakamoto C, Urata Y, et al. Coxsackievirus B3 is an Oncolytic Virus With Immunostimulatory Properties That is Active Against Lung Adenocarcinoma. Cancer Res (2012) 72 (10):2609-21. doi: 10.1158/0008-5472.CAN-11-3185

34. Donnelly OG, Errington-Mais F, Steele L, Hadac E, Jennings V, Scott K, et al. Measles Virus Causes Immunogenic Cell Death in Human Melanoma. Gene Ther (2013) 20(1):7-15. doi: 10.1038/gt.2011.205

35. Garrido G, Rabasa A, Sanchez B, Lopez MV, Blanco R, Lopez A, et al. Induction of Immunogenic Apoptosis by Blockade of Epidermal Growth Factor Receptor Activation With a Specific Antibody. J Immunol (2011) 187 (10):4954-66. doi: 10.4049/jimmunol.1003477

36. Pozzi C, Cuomo A, Spadoni I, Magni E, Silvola A, Conte A, et al. The EGFRSpecific Antibody Cetuximab Combined With Chemotherapy Triggers Immunogenic Cell Death. Nat Med (2016) 22(6):624-31. doi: 10.1038/nm.4078

37. Liu P, Zhao L, Pol J, Levesque S, Petrazzuolo A, Pfirschke C, et al. CrizotinibInduced Immunogenic Cell Death in Non-Small Cell Lung Cancer. Nat Commun (2019) 10(1):1486. doi: 10.1038/s41467-019-09415-3

38. Liu P, Zhao L, Kepp O, Kroemer G. Crizotinib - A Tyrosine Kinase Inhibitor That Stimulates Immunogenic Cell Death. Oncoimmunology (2019) 8 (7):1596652. doi: 10.1080/2162402X.2019.1596652

39. Turubanova VD, Balalaeva IV, Mishchenko TA, Catanzaro E, Alzeibak R, Peskova NN, et al. Immunogenic Cell Death Induced by a New Photodynamic Therapy Based on Photosens and Photodithazine. I Immunother Cancer (2019) 7(1):350. doi: 10.1186/s40425-019-0826-3

40. Liang R, Liu L, He H, Chen Z, Han Z, Luo Z, et al. Oxygen-Boosted Immunogenic Photodynamic Therapy with Gold nanocages@manganese dioxide to Inhibit Tumor Growth and Metastases. Biomaterials (2018) 177:149-60. doi: 10.1016/j.biomaterials.2018.05.051

41. Liu H, Hu Y, Sun Y, Wan C, Zhang Z, Dai X, et al. Co-delivery of Bee Venom Melittin and a Photosensitizer with an Organic-Inorganic Hybrid Nanocarrier for Photodynamic Therapy and Immunotherapy. ACS Nano (2019) 13 (11):12638-52. doi: 10.1021/acsnano.9b04181

42. Yang W, Zhu G, Wang S, Yu G, Yang Z, Lin L, et al. In Situ Dendritic Cell Vaccine for Effective Cancer Immunotherapy. ACS Nano (2019) 13(3):308394. doi: 10.1021/acsnano.8b08346

43. Deng H, Zhou Z, Yang W, Lin LS, Wang S, Niu G, et al. Endoplasmic Reticulum Targeting to Amplify Immunogenic Cell Death for Cancer Immunotherapy. Nano Lett (2020) 20(3):1928-33. doi: 10.1021/acs.nanolett.9b05210

44. Lau TS, Chan LKY, Man GCW, Wong CH, Lee JHS, Yim SF, et al. Paclitaxel Induces Immunogenic Cell Death in Ovarian Cancer Via TLR4/IKK2/ SNARE-Dependent Exocytosis. Cancer Immunol Res (2020) 8(8):1099-111. doi: 10.1158/2326-6066.CIR-19-0616

45. Schirrmacher V. Oncolytic Newcastle Disease Virus as a Prospective AntiCancer Therapy. A Biologic Agent With Potential to Break Therapy Resistance. Expert Opin Biol Ther (2015) 15(12):1757-71. doi: 10.1517/ 14712598.2015 .1088000
46. Ma J, Ramachandran M, Jin C, Quijano-Rubio C, Martikainen M, Yu D, et al. Characterization of Virus-Mediated Immunogenic Cancer Cell Death and the Consequences for Oncolytic Virus-Based Immunotherapy of Cancer. Cell Death Dis (2020) 11(1):48. doi: 10.1038/s41419-020-2236-3

47. Yamano T, Kubo S, Fukumoto M, Yano A, Mawatari-Furukawa Y, Okamura $\mathrm{H}$, et al. Whole Cell Vaccination Using Immunogenic Cell Death by an Oncolytic Adenovirus is Effective Against a Colorectal Cancer Model. Mol Ther Oncolytics (2016) 3:16031. doi: 10.1038/mto.2016.31

48. Newman JH, Chesson CB, Herzog NL, Bommareddy PK, Aspromonte SM, Pepe R, et al. Intratumoral Injection of the Seasonal Flu Shot Converts Immunologically Cold Tumors to Hot and Serves as an Immunotherapy for Cancer. Proc Natl Acad Sci U S A (2020) 117(2):1119-28. doi: 10.1073/ pnas. 1904022116

49. Kanaya N, Kuroda S, Kakiuchi Y, Kumon K, Tsumura T, Hashimoto M, et al. Immune Modulation by Telomerase-Specific Oncolytic Adenovirus Synergistically Enhances Antitumor Efficacy With Anti-PD1 Antibody. Mol Ther (2020) 28(3):794-804. doi: 10.1016/j.ymthe.2020.01.003

50. Kabiljo J, Laengle J, Bergmann M. From Threat to Cure: Understanding of Virus-Induced Cell Death Leads to Highly Immunogenic Oncolytic Influenza Viruses. Cell Death Discov (2020) 6:48. doi: 10.1038/s41420-020-0284-1

51. Aaes TL, Kaczmarek A, Delvaeye T, De Craene B, De Koker S, Heyndrickx L, et al. Vaccination With Necroptotic Cancer Cells Induces Efficient Anti-Tumor Immunity. Cell Rep (2016) 15(2):274-87. doi: 10.1016/ j.celrep.2016.03.037

52. Obeid M, Panaretakis T, Joza N, Tufi R, Tesniere A, van Endert $P$, et al. Calreticulin Exposure is Required for the Immunogenicity of GammaIrradiation and UVC Light-Induced Apoptosis. Cell Death Differ (2007) 14 (10):1848-50. doi: 10.1038/sj.cdd.4402201

53. Tang H, Xu X, Chen Y, Xin H, Wan T, Li B, et al. Reprogramming the Tumor Microenvironment Through Second-Near-Infrared-Window Photothermal Genome Editing of PD-L1 Mediated by Supramolecular Gold Nanorods for Enhanced Cancer Immunotherapy. Adv Mater (2021) 33(12):e2006003. doi: 10.1002/adma.202006003

54. Alzeibak R, Mishchenko TA, Shilyagina NY, Balalaeva IV, Vedunova MV, Krysko DV. Targeting Immunogenic Cancer Cell Death by Photodynamic Therapy: Past, Present and Future. J Immunother Cancer (2021) 9(1):1-22. doi: 10.1136/jitc-2020-001926

55. Agostinis P, Berg K, Cengel KA, Foster TH, Girotti AW, Gollnick SO, et al. Photodynamic Therapy of Cancer: An Update. CA Cancer J Clin (2011) 61 (4):250-81. doi: 10.3322/caac.20114

56. Cheng Y, Cheng H, Jiang C, Qiu X, Wang K, Huan W, et al. Perfluorocarbon Nanoparticles Enhance Reactive Oxygen Levels and Tumour Growth Inhibition in Photodynamic Therapy. Nat Commun (2015) 6:8785. doi: 10.1038/ncomms9785

57. Qiu GZ, Jin MZ, Dai JX, Sun W, Feng JH, Jin WL. Reprogramming of the Tumor in the Hypoxic Niche: The Emerging Concept and Associated Therapeutic Strategies. Trends Pharmacol Sci (2017) 38(8):669-86. doi: 10.1016/j.tips.2017.05.002

58. Chen Z, Liu L, Liang R, Luo Z, He H, Wu Z, et al. Bioinspired Hybrid Protein Oxygen Nanocarrier Amplified Photodynamic Therapy for Eliciting AntiTumor Immunity and Abscopal Effect. ACS Nano (2018) 12(8):8633-45. doi: $10.1021 / a c s n a n o .8 b 04371$

59. Cai Z, Xin F, Wei Z, Wu M, Lin X, Du X, et al. Photodynamic Therapy Combined With Antihypoxic Signaling and CpG Adjuvant as an In Situ Tumor Vaccine Based on Metal-Organic Framework Nanoparticles to Boost Cancer Immunotherapy. Adv Healthc Mater (2020) 9(1):e1900996. doi: 10.1002/adhm.201900996

60. Wang Q, Ju X, Wang J, Fan Y, Ren M, Zhang H. Immunogenic Cell Death in Anticancer Chemotherapy and its Impact on Clinical Studies. Cancer Lett (2018) 438:17-23. doi: 10.1016/j.canlet.2018.08.028

61. Lee P, Gujar S. Potentiating Prostate Cancer Immunotherapy With Oncolytic Viruses. Nat Rev Urol (2018) 15(4):235-50. doi: 10.1038/ nrurol.2018.10

62. Hinterberger M, Giessel R, Fiore G, Graebnitz F, Bathke B, Wennier S, et al. Intratumoral Virotherapy With 4-1BBL Armed Modified Vaccinia Ankara Eradicates Solid Tumors and Promotes Protective Immune Memory. J Immunother Cancer (2021) 9(2):1-13. doi: 10.1136/jitc-2020-001586 
63. Kohlhapp FJ, Kaufman HL. Molecular Pathways: Mechanism of Action for Talimogene Laherparepvec, a New Oncolytic Virus Immuno therapy. Clin Cancer Res (2016) 22(5):1048-54. doi: 10.1158/1078-0432. CCR-15-2667

64. Jessup JM, Kabbout M, Korokhov N, Joun A, Tollefson AE, Wold WSM, et al. Adenovirus and Oxaliplatin Cooperate as Agnostic Sensitizers for Immunogenic Cell Death in Colorectal Carcinoma. Hum Vaccin Immunother (2020) 16(3):636-44. doi: 10.1080/21645515.2019.1665960

65. Garrido G, Lorenzano P, Sanchez B, Beausoleil I, Alonso DF, Perez R, et al. T Cells are Crucial for the Anti-Metastatic Effect of Anti-Epidermal Growth Factor Receptor Antibodies. Cancer Immunol Immunother (2007) 56 (11):1701-10. doi: 10.1007/s00262-007-0313-4

66. Menger L, Vacchelli E, Adjemian S, Martins I, Ma Y, Shen S, et al. Cardiac Glycosides Exert Anticancer Effects by Inducing Immunogenic Cell Death. Sci Transl Med (2012) 4(143):143ra99. doi: 10.1126/scitranslmed.3003807

67. Fletcher R, Tong J, Risnik D, Leibowitz BJ, Wang YJ, Concha-Benavente F, et al. Non-Steroidal Anti-Inflammatory Drugs Induce Immunogenic Cell Death in Suppressing Colorectal Tumorigenesis. Oncogene (2021) 40 (11):2035-50. doi: 10.1038/s41388-021-01687-8
68. Huang J, Chen P, Liu K, Liu J, Zhou B, Wu R, et al. CDK1/2/5 Inhibition Overcomes IFNG-mediated Adaptive Immune Resistance in Pancreatic Cancer. Gut (2021) 70(5):890-9. doi: 10.1136/gutjnl-2019320441

69. Bertheloot D, Latz E, Franklin BS. Necroptosis, Pyroptosis and Apoptosis: An Intricate Game of Cell Death. Cell Mol Immunol (2021) 18(5):1106-21. doi: 10.1038/s41423-020-00630-3

Conflict of Interest: The authors declare that the research was conducted in the absence of any commercial or financial relationships that could be construed as a potential conflict of interest.

Copyright (c) 2021 Jin and Wang. This is an open-access article distributed under the terms of the Creative Commons Attribution License (CC BY). The use, distribution or reproduction in other forums is permitted, provided the original author(s) and the copyright owner(s) are credited and that the original publication in this journal is cited, in accordance with accepted academic practice. No use, distribution or reproduction is permitted which does not comply with these terms. 